\title{
pro.posições
}

$e$-ISSN 1980-6248

http://dx.doi.org/10.1590/1980-6248-2015-0098

ARTIGOS

\section{A trajetória do educador Paulo Freire no Ministério da Educação e Cultura no período de 1958 a 1963}

\section{The trajectory of the educator Paulo Freire in the Ministry of Education and Culture from 1958 to 1963}

Resumo: O trabalho analisa a pouco conhecida trajetória do intelectual Paulo Freire no Centro Regional de Pesquisas Educacionais do Recife (CRPE-RE) no período de 1958 a 1963 na gestão do sociólogo Gilberto Freyre. Cabe lembrar que o CRPERE estava ligado ao Centro Brasileiro de Pesquisas Educacionais (CBPE) sob a direção de Anísio Teixeira. O artigo busca mapear essa atuação, entender os motivos do seu esquecimento por parte dos estudiosos da obra freiriana e a ausência desta trajetória nos livros do próprio Paulo Freire. O que instiga a pensar num jogo de espelhos entre a memória e o esquecimento que nos conduzem aos seguintes questionamentos sobre a referida trajetória: qual a efetiva participação de Paulo Freire no cotidiano do CRPE-RE? Houve um autoapagamento desta experiência? Ou seguiu os passos da tentativa de esquecimento que recaiu sobre o CBPE, após 1964? A fim de compreender tais questões, a metodologia utilizada repousa na pesquisa de caráter documental e histórico. A fonte primária é o Boletim Mensal do Centro Brasileiro de Pesquisas Educacionais, uma publicação do Instituto Nacional de Estudos Pedagógicos no âmbito do Ministério da Educação. A rigor, busca-se o cotejamento entre o dito nos diversos livros do autor e o escrito no referido Boletim. Palavras-chave: Paulo Freire, história e memória, centro regional de pesquisas educacionais do Recife, boletim mensal do centro brasileiro de pesquisas educacionais, Ministério da Educação e Cultura, 1958-1963 


\section{pro.posições}

$e$-ISSN 1980-6248

http://dx.doi.org/10.1590/1980-6248-2015-0098

Abstract: This paper analyzes the lesser known work of the intellectual Paulo Freire at the Centro Regional de Pesquisas Educacionais do Recife (CRPE-RE; Regional Center of Educational Researches of Recife) between the years 1958 and 1963 during the management period of the sociologist Gilberto Freyre. It is important to point out that the CRPE-RE was connected to the Centro Brasileiro de Pesquisas Educacionais (CBPE; Bravilian Center of Educational Researches) under the administration of Anisio Teixeira. This article aims to map this work, to understand the reasons why researches in Freire's work have forgotten it, and the absence of this work in the Freire's own books. This points towards the ambiguity between memory and oblivion that conducts to the questioning of Freire's path: What is the real role of Paulo Freire in the daily routine of CRPE-RE? W as there any self-deletion of this experience? Or has it followed the steps of the attempt to erase the memory of the CBPE, underway after 1964? In order to understand these questions, the methodology used is based on a documental and historical research. The Boletim Mensal (Monthly Report) of the CBPE, published by the Instituto Nacional de Estudos Pedagógicos (National Institute for Pedagogical Researches), is the primary source for this study. The main objective is to compare what is written in Freire's many books to what is found in these reports.

Keywords: Paulo Freire, history and memory, Regional Center of Educational Researches of Recife, Monthly Report of the Brazilian Center of Educational Researches, Ministry of Education and Culture, 1958-1963

Este texto tem como objeto de estudo a trajetória do intelectual ${ }^{1}$ Paulo Freire no Centro Regional de Pesquisas Educacionais do Recife (CRPE-Recife) no período de 1958 a 1963 e, como fonte principal, o Boletim Mensal do Centro Brasileiro de Pesquisas Educacionais $(\mathrm{CBPE})^{2}$.

A rigor, busca estabelecer aproximações entre o trabalho de Freire no Serviço Social da Indústria (SESI até 1957), como professor de História e Filosofia da Educação da Universidade de Pernambuco (a partir de 1958), nos projetos desenvolvidos no Centro Regional de Pesquisas Educacionais do Recife (1958 a 1963) e suas primeiras experiências de alfabetização (a partir de 1963).

\footnotetext{
${ }^{1}$ Sobre trajetórias de intelectuais, examinar: Vale, A. (2006). O ISEB, os intelectuais e a diferenç: um diálogo teimoso na educação. São Paulo, SP: Editora UNESP; Miceli, S. (2001). Intelectuais à brasileira. São Paulo: Companhia das Letras; Bobbio, N. (1997). Os intelectuais e o poder: dúvidas e opções dos homens de cultura na sociedade contemporânea. São Paulo: Editora UNESP.

2 O Centro Brasileiro de Pesquisas Educacionais foi criado em 1955 com cinco Centros Regionais de Pesquisa Educacional, a saber: Recife, São Paulo, Minas Gerais, Bahia e Rio Grande do Sul. Mais informações, ver: Gouvêa, F. (2010). O impresso como estratégia de legitimação do Centro Brasileiro de Pesquisas Educacionais (1955-1964). Anais do II Encontro de História da Educação do Estado do Rio de Janeiro. Rio de Janeiro.
} 


\section{pro.posições}

$e$-ISSN 1980-6248

http://dx.doi.org/10.1590/1980-6248-2015-0098

A metodologia utilizada repousa na pesquisa de caráter documental e histórico, especialmente no que concerne à história cultural $^{3}$ que valoriza fontes variadas como os impressos ${ }^{4}$ (periódicos, boletins, revistas). Cabe observar que haverá uma imbricação entre as fontes utilizadas e a biografia ${ }^{5}$ de Freire, disponível no sítio do Instituto Paulo Freire.

No campo conceitual, as palavras memória e esquecimento - na perspectiva deste trabalho - são faces de uma mesma moeda. Mais do que isto, acompanhando o raciocínio de Halbwacks (2006), entende-se que, mesmo inserida num processo de intensa negociação com o indivíduo, toda memória é coletiva, pois

se a memória coletiva tira sua força e sua duração por ter como base um conjunto de pessoas, são os indivíduos que se lembram, enquanto integrantes do grupo. Desta massa de lembranças comuns, umas apoiadas nas outras, não serão as mesmas que aparecerão com maior intensidade a cada um deles. De bom grado, diríamos que cada memória individual é um ponto de vista sobre a memória coletiva, que este ponto de vista muda segundo o lugar que ali ocupo e que esse mesmo lugar muda segundo as relações que mantenho com outros ambientes. (p. 69)

O argumento de Halbwacks (2006) contribui para a seguinte reflexão: teria Paulo Freire, no jogo de espelhos entre "memória" e "esquecimento", operado o próprio apagamento de sua participação no CRPE-Recife por força de sua atuação em diferentes planos de memória de um grupo? Num espaço em que "se destacam as lembranças dos eventos e das experiências que dizem respeito à maioria de seus membros e que resultam da sua própria vida ou de suas relações com os grupos mais próximos” (p. 51). Como grupos mais próximos, é possível assinalar o SESI e a Universidade do Recife nas redes de sociabilidade de Freire em detrimento do CRPE-Recife.

\footnotetext{
${ }^{3}$ Sobre História Cultural, verificar: Chartier, R. (1990). A História cultural: entre práticas e representações. Lisboa: Difel. Pesavento, S. J. (2003). História \& História cultural. Belo Horizonte: Autêntica.

${ }^{4}$ Especificamente, no tocante à valorização do impresso como objeto ou fonte de pesquisa, ver: Catani, D. B., \& Bastos, M. H. C. (Orgs.). (2002). Educação em revista: a imprensa periódica e a história da educação. São Paulo: Escrituras; Mendonça, A. W. P. C. (Org.). (2010). História e Educação: dialogando com as fontes. Rio de Janeiro: Forma \& Ação.

${ }^{5}$ Sobre as tensões e interdições no campo da biografia, ler: Bordieu, P. (2002). A ilusão biográfica. In M. de M. Ferreira, \& J. Amado, J. (Orgs.), Usos e abusos da bistória oral. Rio de Janeiro: Editora FGV; Levillain, P. (2003). Os protagonistas da biografia. In R. Rémond (Org.), Por uma história política. Rio de Janeiro: Editora FGV.
} 


\section{pro.posıções}

$e$-ISSN 1980-6248

http://dx.doi.org/10.1590/1980-6248-2015-0098

O esquecimento chama a atenção pelo fato de que, mesmo nos livros de sua autoria no formato de entrevista ${ }^{6}$ ou, parafraseando Becker (2002), de "memórias provocadas" (p. 28), com utilização da metodologia da história oral ${ }^{7}$, a experiência no CRPE-Recife não se fez presente ${ }^{8}$.

Ainda no campo dos conceitos, a palavra intelectual" terá sempre a conotação de "ator do político", de ator que apresenta "um engajamento na vida da cidade" e dos seus projetos e que também pode ser a testemunha ou a consciência destes movimentos no que se refere à assinatura de manifestos e abaixo-assinados, criação de revistas e demais ações que se estendam a outros campos sociais (Sirinelli, 2003, p. 231).

Há que se destacar que se trata de um ator do político que opera em rede. Segundo Elias (1994), nessa rede

muitos fios isolados ligam-se uns aos outros. No entanto, nem a totalidade da rede nem a forma assumida por cada um dos seus fios podem ser compreendidas em termos de um único fio, ou mesmo de todos eles, isoladamente considerados; a rede só é compreensível em termos da maneira como eles se ligam, de sua relação recíproca. Essa ligação origina um sistema de tensões para o qual cada fio isolado concorre, cada um de uma maneira um pouco diferente, conforme seu lugar e função na totalidade da rede. (p. 35)

Apresenta-se instigante a possibilidade de conhecer como Freire se emaranhou na rede formada pelo CRPE-Recife e quais as estratégias que lançou mão para alcançar os seus objetivos no âmbito da referida instituição. Estratégia que, no dizer de Certeau (2004), se apresenta como

o cálculo (ou manipulação) das relações de força que se torna possível a partir do momento em que um sujeito de querer e poder (uma empresa, um exército, uma cidade, uma instituição científica) pode ser isolado. A estratégia postula um lugar suscetível de ser circunscrito como algo próprio e ser a base de onde se podem gerir as relações com uma exterioridade de alvos ou

\footnotetext{
${ }^{6}$ Por exemplo: Freire, P., \& Guimarães, S. (1984). Sobre Educação: diálogos. Rio de Janeiro: Paz e Terra; Freire, P. \& Faundez, A. (1985). Por uma pedagogia da pergunta. Rio de Janeiro: Paz e Terra; Freire, P., \& Shor, I. (1986). Medo e ousadia - o cotidiano do professor. Rio de Janeiro: Paz e Terra; Freire, P., \& Betto, F. (1987). Essa escola chamada vida: depoimentos ao repórter Ricardo Kotscho. São Paulo: Ática; Freire, P., \& Guimarães, S. (1987). Aprendendo com a própria história. Rio de Janeiro: Paz e Terra; Freire, P., \& Nogueira, A. (1991). Que fazer: teoria e prática em educação popular. Petrópolis: Vozes.

${ }^{7}$ Sobre história oral, ver: Ferreira, M. de M. \& Amado, J. (Orgs.). (2002). Usos e abusos da história oral. Rio de Janeiro: Editora FGV.

8 A fim de capturar com acuidade as memórias provocadas e os esquecimentos do intelectual em tela, serão utilizados apenas os livros escritos pelo próprio Freire.

${ }^{9}$ Sobre as relações entre os intelectuais e a modernidade, consultar: Berman, M. (2010). Rukia riu de si mesma: intelectuais e modernidade. In D. A. Reis et al. (Orgs.), Tradiçoes e modernidades. Rio de Janeiro: Editora FGV.
} 


\section{pro.posições}

$e$-ISSN 1980-6248

http://dx.doi.org/10.1590/1980-6248-2015-0098

ameaças ... toda racionalização estratégica procura em primeiro lugar distinguir de um ambiente um próprio [ênfases no original], isto é, o lugar do poder e do querer próprios. (p. 99)

A citação de Certeau permite pensar quais foram os embates e as dissensões no âmbito institucional, símbolos da luta pelo poder ou hegemonia, que acabaram por ocasionar uma participação modesta de Freire diante das possibilidades ora abertas ora interditadas.

Apresentados os conceitos básicos, torna-se necessário esclarecer a estrutura do artigo: num primeiro momento, será trabalhado o contexto histórico do período em tela e a criação do CBPE; num segundo tempo, o texto se debruçará na criação e na organização do CRPE-Recife e, por fim, o foco recairá na atuação de Paulo Freire no âmbito da citada instituição.

\section{O contexto histórico e a criação do Centro Brasileiro de Pesquisas Educacionais: os anos 1950 e 1960}

Num momento histórico marcado pelo modelo econômico nacionaldesenvolvimentista ${ }^{10}$ e por uma sociedade em movimento de urgência por mudanças, foi decisiva a tentativa de estabelecimento de novos paradigmas para a necessária solução de antigas e novas inquietações presentes nos diferentes campos de análise, tendo o planejamento e a ciência como pilares de sustentação para a procura da porta de saída de uma sociedade arcaica e dita atrasada e o encontro da porta de entrada numa sociedade moderna e civilizadora (Botelho, Bastos, \& Boas, 2008).

A compreensão da dinâmica dos anos 1950 e 1960 solicita o aprofundamento em duas dimensões distintas e complementares desse momento histórico: a primeira dimensão refere-se às formas próprias do processo de organização da sociedade articuladas e expressas na consolidação do Estado brasileiro, numa tentativa de identificar que tipo de Estado concebeu a criação de diversas instituições e a partir de que conjuntura de interesses e forças políticas que estavam em situação concorrencial; enquanto a segunda dimensão objetiva situar as matrizes

10 Para a compreensão histórica desse período, ver: Fausto, B. (2012). História do Brasil. São Paulo: EDUSP, especificamente o capítulo 8. No tocante aos desdobramentos do referido arco de tempo no campo educacional, consultar: Saviani, D. (2011). História das ideias pedagógicas no Brasil (capítulo X). São Paulo: Autores Associados. 


\section{pro.posıções}

$e$-ISSN 1980-6248

http://dx.doi.org/10.1590/1980-6248-2015-0098

econômico-produtivas presentes no momento de criação da Instituição que influenciaram o seu surgimento (Sanchez \& Gouvêa, 2011).

Palco de quatro governos distintos e - ao mesmo tempo - complementares: o governo de Getúlio Vargas (1951-1954), o de Juscelino Kubitschek (1956-1960), o governo Jânio Quadros (1961) e o de João Goulart (1961-1964) refletiram o tipo de Estado que vinha se consolidando no Brasil, o que remete ao longo processo de transição que caracterizou o desenvolvimento do capitalismo industrial no País.

Os anos em tela, segundo Ferreira e Delgado (2003), formaram o "Tempo da Experiência Democrática". Na verdade, uma democracia frágil que já fora quebrada em 1937 com o golpe do Estado Novo e, novamente solapada, pelo Golpe Civil Militar de 1964. Cabe asseverar que os autores não consideram o período de 1945 a 1964 uma democracia consolidada, mas em fase de experiências e ensaios democráticos. Portanto, foi neste contexto que surgiram o Centro Brasileiro de Pesquisas Educacionais ${ }^{11}$ e os Centros Regionais de Pesquisas Educacionais.

Ao longo desses anos, foram consolidados modelos de crescimento econômico pautados numa industrialização acelerada, centrada no Poder Executivo, que desencadeou o crescimento do setor público e diversificou suas atividades internas, concretizando as exigências de uma sociedade urbano-industrial em expansão e acelerando as transformações institucionais, instaurando uma estrutura de poder mais adequada às tendências da nova configuração econômico-social e mais complexa do que a anterior (Gouvêa, 2001).

Seguindo as trilhas deste raciocínio, cabe destacar que, dentre as várias instituições criadas para a tentativa de soluções para a questão educacional no panorama apontado, está o Centro Brasileiro de Pesquisas Educacionais (CBPE), criado em 1955 pelo Decreto n. 38.460 no âmbito do Ministério da Educação e Cultura. A compreensão da criação do CBPE passa efetivamente pelo Instituto Nacional de Estudos Pedagógicos (INEP) ${ }^{12}$, especificamente pela

\footnotetext{
11 Para o entendimento da estrutura e da organização do CBPE, ver: Xavier, L. N. (1999). O Brasil como laboratório: educação e ciências sociais no projeto do Centro Brasileiro de Pesquisas Educacionais CBPE/INEP/MEC (1950-1960). Tese de Doutorado, Departamento de Educação, PUC-Rio.

12 Atualmente, Instituto Nacional de Estudos e Pesquisas Educacionais Anísio Teixeira.
} 


\section{pro.posıções}

$e$-ISSN 1980-6248

http://dx.doi.org/10.1590/1980-6248-2015-0098

gestão do intelectual Anísio Teixeira e seus colaboradores ${ }^{13}$ a partir de 1952. Segundo Freitas (1999), o Centro Brasileiro de Pesquisas Educacionais e os Centros Regionais de Pesquisas Educacionais representaram o esforço de aproximação e diálogo entre o conhecimento da situação local e o da questão nacional.

Ainda no tocante à criação dos Centros Regionais de Pesquisas Educacionais, Ferreira (2008) assinala que

a entrada em funcionamento dos Centros de Pesquisas Educacionais do INEP14, a partir de 1955, já foi avaliada como parte integrante de um movimento mais amplo de intensificação da ação governamental no sentido da construção de aparatos oficiais destinados ao estudo e ao planejamento no campo educacional que contou com o envolvimento de parte importante de uma geração de destacados cientistas sociais com a temática educacional . (pp.279-280)

Neste sentido, entende-se que três estratégias foram lançadas para a tentativa de sustentação de uma análise do papel exercido pelo CBPE na gestão de Teixeira. São elas: estratégias de articulação (as instâncias organizacionais internas do CBPE em constante comunicação); estratégias de irradiação (a utilização dos instrumentos de divulgação das iniciativas do CBPE, através de periódicos dentre os quais, vale ressaltar o Boletim Mensal do CBPE e a revista Educação e Ciências Sociais) ${ }^{15}$; estratégias de intervenção (o trabalho desenvolvido pelo CBPE e, consequentemente, pelos CRPEs numa filosofia que penso estar traduzida no máximo envolvimento de todos os atores, num processo contínuo, para a legitimação de práticas pedagógicas exemplares para as escolas e para os docentes). Tal perspectiva reforça a ideia de um projeto coletivo, ou seja, de um grupo sob o comando de Teixeira que, para além das finalidades específicas, teve a intenção de construir marcos no campo educacional e operar intervenções no fazer docente e no fazer da escola, especialmente no que concerne ao currículo escolar e ao planejamento educacional.

O Boletim do CBPE - fonte privilegiada para a consecução deste artigo - tinha a periodicidade mensal. Foram analisados 77 boletins com uma média de 20 páginas por número.

\footnotetext{
${ }^{13}$ Dentre os colaboradores de Teixeira, destaco os intelectuais Jayme Abreu e João Roberto Moreira. Sobre esses atores, ler: Fávero, M. de L. de A., \& Brito, J. de M. (Orgs.). (1999). Dicionário de educadores no Brasil: da colônia aos dias atuais. Rio de Janeiro: Ed. UFRJ e MEC/INEP.

14 A denominação "Centros de Pesquisas Educacionais do INEP" utilizada pela autora não é conflitante com a utilizada neste artigo, haja vista que o CBPE e os seus centros regionais eram subordinados ao INEP.

${ }^{15}$ Sobre a Revista Educação e Ciências Sociais, consultar: Xavier, L. N. (1997). A pesquisa do CBPE em revista. In A. W. P. C. Mendonça, \& Z. Brandão (Orgs.), Por que não lemos Anísio Teixeira? Rio de Janeiro: Ravil.
} 


\section{pro.posıções \\ $e$-ISSN 1980-6248}

http://dx.doi.org/10.1590/1980-6248-2015-0098

O primeiro número foi publicado em agosto de 1957 e estava sob a responsabilidade da Divisão de Documentação e Informação Pedagógica do CBPE.

Os Centros Regionais de Pesquisa Educacional enviavam mensalmente informações do seu trabalho para a publicação no boletim do CBPE. Nem todas as notícias enviadas foram publicadas, pois havia uma comissão editorial que depurava as informações relevantes para a instituição.

Neste estudo, estão estabelecidas duas fases em relação à vida institucional do CBPE: um primeiro período que cobriu os anos de 1957 a 1960, período de consolidação e legitimação no plano regional, nacional e pan-americano; um segundo período de intensa dispersão dos quadros intelectuais da instituição por uma excessiva preocupação com a implementação da Universidade de Brasília e com a possibilidade de intervenção no sistema educacional via o assento no Conselho Federal de Educação. O segundo período ocorreu no arco de tempo de 1961 a 1964.

No próximo bloco, serão analisadas a gênese, a organização e os projetos de pesquisa desenvolvidos pelo Centro Regional de Pesquisas Educacionais do Recife. Cabe ressaltar que a periodização utilizada no estudo do CBPE será reafirmada no estudo específico do referido Centro Regional.

\section{Centro Regional de Pesquisas Educacionais do Recife (CRPE-}

\section{Recife)}

Último Centro Regional inaugurado (1957), o Centro Regional de Pesquisas Educacionais do Recife apresentou algumas peculiaridades: foi o único centro que teve a sua denominação ligada à cidade sede e não ao estado; o único, também, que adotou o termo "orientador" no lugar de diretor; teve no Instituto Joaquim Nabuco a sua primeira morada. Com forte tradição nos aspectos regionais direcionou o seu raio de ação para as pesquisas educacionais e sociais que, acentuando a regionalidade nordestina, pudessem servir como móvel para a compreensão da cultura e da educação de caráter nacional. Nesses aspectos, a orientação 


\section{pro.posıções}

$e$-ISSN 1980-6248

http://dx.doi.org/10.1590/1980-6248-2015-0098

que Gilberto Freyre imprimiu ao Centro Regional foi imprescindível para o alcance de tais objetivos (Gouvêa, 2008) ${ }^{16}$.

Uma análise das notícias publicadas no Boletim do $\mathrm{CBPE}^{17}$ evidenciou o papel de destaque dado ao referido Centro Regional como local de divulgação das notícias do Nordeste seguindo a orientação de perfil de irradiação regional da educação e da cultura. No que tangencia o aspecto qualitativo, as notícias divulgadas na seção apresentaram um baixo índice de correlação com o estabelecido para o trabalho dos Centros Regionais. Tal situação, em parte, está imbricada com a provisoriedade das instalações do centro e com alguns desentendimentos com a direção do Instituto Joaquim Nabuco, ocasionando falhas e sobressaltos na condução dos projetos de pesquisa que, somente em fins de 1959, tiveram uma divisão específica para organizá-los.

O Centro Regional de Recife esteve na primeira fase (1957-1960) muito próximo ao Centro Regional de Pesquisas Educacionais de São Paulo no tocante às participações no Boletim Mensal. Essa posição de destaque foi consolidada na segunda fase (1961-1963). O alargamento pode ser creditado tanto no sentido quantitativo quanto no qualitativo à zona de influência de Gilberto Freyre. A presença de Freyre à frente do Centro Regional desde o início (1957) até o fim da segunda fase (1963) imprimiu credibilidade e atraiu parcerias que possibilitaram a realização de cursos, seminários e pesquisas, que alcançaram toda a região nordeste numa perspectiva em que o regional serviu de base para o alcance das questões nacionais e internacionais.

Assim, o Centro operou um movimento de transformar uma experiência local e regional num espaço para as experimentações e os intercâmbios com outras ambiências institucionais. A análise reside, portanto, na capacidade criativa de Freyre e sua equipe em responder aos desafios propostos nesta segunda fase de existência do CBPE e dos seus Centros Regionais.

16 A organização do CRPE-Recife seguia os modelos do CBPE, ou seja, uma Divisão de Estudos e Pesquisas Educacionais (DEPE), a Divisão de Estudos e Pesquisas Sociais (DEPS), a Divisão de Aperfeiçoamento do Magistério (DAM) e, por fim, a Divisão de Documentação e Informação Pedagógica.

${ }^{17}$ Não foi possível o acesso à publicação original do CRPE-Recife intitulada Cadernos de Educação e Região que circulou entre 1961 e 1964. Em relação aos estudos sobre este periódico, consultar: Souza, K. F. B. de. (2003). Educação e região. Práticas anisianas e freyreanas fazem a educação do Recife (1957-1964) (233pp.). Tese de Doutorado, Universidade Federal de Pernambuco, Pernambuco. 


\section{pro.posıções}

$e$-ISSN 1980-6248

http://dx.doi.org/10.1590/1980-6248-2015-0098

A sede própria do CRPE-RE abrigou em 1961 a escola de demonstração e atividades outras como seminários mensais internos e externos. O ano de 1962 trouxe os "círculos de palestras sobre arte e educação, o encontro de professoras primárias sobre problemas de psicopedagogia" (Boletim Mensal do CBPE, n.57, p. 13), o seminário “o Recife e seus problemas sociais e educacionais" (Boletim Mensal do CBPE, n. 61, p. 14) e o "I curso de preparação em pesquisas sociais” (Boletim Mensal do CBPE, n. 64, p. 13).

Uma intensa movimentação apenas superada pelo ano seguinte que protagonizou um "curso de programação educacional" para 45 professores do Nordeste, sob o patrocínio da Superintendência do Desenvolvimento do Nordeste (SUDENE), da Aliança para o Progresso e com recursos oriundos do Plano Nacional de Educação, elaborado em 1962 (Boletim Mensal do CBPE, n. 67, p. 17) e um curso de formação de supervisores de ensino (Boletim Mensal do CBPE, n. 73, p. 13). Esse último curso foi um cumprimento das metas de ensino constantes do Plano Trienal de Desenvolvimento Econômico do governo João Goulart. Portanto, trabalhos que entrelaçaram o nacional e o internacional.

Quanto ao aspecto qualitativo, o Centro Regional reverteu o baixo desempenho da primeira fase. O esforço empreendido na formação de pesquisadores e planejadores foi a causa do sucesso das atividades desenvolvidas pelo Centro Regional de Pesquisas Educacionais do Recife. A seguir, uma lista com os temas mais abordados pelos projetos de trabalho - projetos de pesquisas ou levantamentos - aprovados e em andamento no período de 1961 a 1963: Meios informais de educação; Áreas socioeconômicas homogêneas do Nordeste; Plano de Educação para Pernambuco; Realidade e perspectivas em orientação profissional; Recursos econômicos e financeiros para a educação em Pernambuco; Educação no município de Caruaru (Boletim Mensal do CBPE - números: 42 ao 77).

Em recente estudo que teve como fonte os Cadernos Região e Educação, periódico oficial do CRPE-RE, Meucci (2015) aponta a existência de dois momentos do Centro do Recife: "O primeiro, de interesse pelas pesquisas sociais que, ainda que estivessem sob o escrutínio do CBPE, tiveram por base estudos de comunidade e de unidades empíricas menores (como as famílias), além das manifestações de cultura popular" (p. 143). Prossegue a pesquisadora com a afirmação de que esse primeiro momento - (1957 a 1961) - correspondeu à formação do patrimônio do Centro, embora o mesmo não tenha acontecido ao quadro de pesquisadores. Meucci (2015) assinala que o segundo momento se estendeu do final de 1961, período da 


\section{pro.posıções}

$e$-ISSN 1980-6248

http://dx.doi.org/10.1590/1980-6248-2015-0098

aprovação da Lei de Diretrizes e Bases da Educação Nacional, n. 4.024 de 1961, até 1964. Segundo a autora, "houve desligamento definitivo de pesquisadores, fim das pesquisas sociais, ampliação dos serviços de aperfeiçoamento docente acompanhada da definição de uma nova agenda de pesquisas educacionais aplicadas" (p. 143).

Assim, num comparativo entre as fases da trajetória institucional do Centro estabelecidas por Meucci e as definidas anteriormente neste artigo, mesmo trabalhando com fontes diferentes, algumas respostas foram encontradas. Dentre elas, destacam-se o regionalismo da primeira fase e, consequentemente, a baixa participação no Boletim Mensal do Centro Brasileiro de Pesquisas Educacionais e - as mais significativas para este trabalho -, a saber: o estabelecimento de parcerias nacionais e internacionais para a obtenção de recursos financeiros para as pesquisas e o intenso desligamento de pesquisadores do CRPE-RE. Sobretudo, o desligamento de Paulo Freire.

Torna-se necessária, na próxima parte deste artigo, a compreensão da participação de Paulo Freire no Centro Regional de Pesquisas Educacionais do Recife.

\section{A presença de Paulo Freire no CRPE-Recife}

O objetivo desta última parte do texto é evidenciar a atuação do intelectual Paulo Freire no cotidiano institucional do CRPE-Recife ${ }^{18}$, buscando tornar públicas as estratégias utilizadas pelo ator em tela nos debates e embates, na proposição de projetos de pesquisa, nas palestras realizadas para os professores e demais profissionais do Centro e, por fim, no afastamento das atividades no ano de 1963 com a recusa tácita de contribuir com a Campanha Nacional de Erradicação do Analfabetismo (CNEA) ${ }^{19}$.

Dar voz ao Boletim Mensal do Centro Brasileiro de Pesquisas Educacionais torna-se a forma mais eficiente para marcar a presença de Freire no Centro Regional. Uma opção que pode ser justificada pelo ineditismo dessa fonte no campo da historiografia da educação brasileira.

${ }^{18}$ Não é objetivo deste artigo traçar a biografia de Paulo Freire. Trata-se de compreender a trajetória - ainda não estudada - deste intelectual no CRPE-RE. Para aqueles que desejam conhecer a bibliografia do educador, consultar: Gadotti, M. (1996). (Org.). Paulo Freire: uma biobibliografia. São Paulo: Cortez.

19 A Campanha Nacional de Erradicação do Analfabetismo (CNEA) foi criada em 1958, pelo Ministério da Educação (MEC), como um programa experimental. 


\section{pro.posições}

$e$-ISSN 1980-6248

Cabe, neste momento, jogar luzes no registro da participação do nosso intelectual no CRPE-

Recife. Assim, análises ou problematizações ficarão para as considerações finais.

A primeira presença de Freire foi registrada na apresentação dos projetos de pesquisa que seriam avaliados para a execução no ano de 1958. Nesta lista, Freire propôs um estudo sobre o "Vocabulário infantil da criança de 7 a 12 anos, em Pernambuco" (Boletim Mensal do CBPE, n. 07, fevereiro, 1958).

Quatro projetos de trabalho já foram apresentados, devendo começar a execução dos três últimos imediatamente. A do primeiro está em realização, desde novembro do ano p. passado. São os seguintes os projetos de trabalho acima mencionados: 1- Mobilidade espacial e estrutural social em pequenas comunidades do nordeste brasileiro - Levi Cruz. 2. Interpretação da literatura infanto-juvenil no Nordeste - Paulo Silveira Rosas. 3. Ideologia dos poetas populares do Nordeste - Renato Accioly Carneiro Campos. 4. Construção de programa de ensino primário adaptados às necessidades de cultura e integração social da escola ao meio - Isnar Cabral de Moura. Outros dois Projetos foram apresentados e estão em estudo: 5. A formação do magistério primário no Nordeste - Itamar de Abreu Vasconcelos [e] 6. Vocabulário infantil da criança de 7 a 12 anos, em Pernambuco - Paulo R. Neves Freire. ${ }^{20}$ (p. 5)

O trecho retirado do Boletim permite esclarecer a estratégia de envolvimento do intelectual nas atividades do CRPE-Recife haja vista a solicitação de verbas para um projeto de pesquisa sobre vocabulário infantil. De certa forma, uma tentativa de pertencer à rede de intelectuais que compunham um espaço voltado para a pesquisa e que, também, foi uma referência na consecução de estudos educacionais da região nordeste. Uma referência ao mesmo estudo reapareceu no Boletim do CBPE em 1959, n. 20, março:

Relação geral dos projetos de pesquisa apresentados às divisões de estudos e pesquisas educacionais e estudos e pesquisas sociais do Centro Regional de Recife, a partir da sua fundação em 18 de novembro de 1957 até 31 de dezembro de 1958 ... 2. CRR-6-DEPE - 4/57 - Paulo Neves Freire. (p. 12)

$\mathrm{Na}$ lista completa aparecem 5 projetos de 1957 e 13 de 1958. Uma nota encerra a informação "Dentre os projetos acima relacionados alguns estão em desenvolvimento e outros aguardando oportunidade para início, ou em estudo para a aprovação". O projeto de Freire

${ }^{20}$ A grafia original foi mantida em todas as citações retiradas do Boletim. 


\section{pro.posições}

$e$-ISSN 1980-6248

http://dx.doi.org/10.1590/1980-6248-2015-0098

estava na segunda categoria, ou seja, sem a aprovação necessária para a alocação de verbas e para a sua execução. ${ }^{21}$

Esse projeto não foi selecionado para o recebimento de verbas por parte do Centro Regional e não foram encontrados o cronograma e o planejamento do projeto de pesquisa. Segundo Meucci (2015), “o projeto teve seu desenvolvimento interrompido por solicitação do CBPE” (p. 137). Tal informação foi retirada dos Cadernos Região e Educação.

No que tange às atividades de formação de pesquisadores e professores, a primeira efetiva participação, ao menos registrada, de Paulo Freire ocorreu no curso "Política e administração escolar no nordeste brasileiro" no ano de 1958 com um total de 20 conferências que versaram sobre os problemas de administração escolar e a política educacional do nordeste brasileiro e, ainda, uma introdução à história do ensino no Nordeste nos anos de 1933 a 1958. Segue um trecho da divulgação do curso.

Já na nova sede do CRPE foram realizadas as conferências do ex-secretário de Educação da Paraíba, Prof. José Rafael de Menezes, sôbre "Educação e política, suas relações no meio nordestino", com debates travados com a participação dos professôres Cláudio Souto, Carlos Maciel e Rui Belo e a [conferência] do Cônego Helio Souza, ex-secretário de Educação de Alagoas, "Reflexões humanísticas sobre o ensino oficial no nordeste", que foi comentada pelos professôres Paulo Freire e Carlos Maciel, tendo vários outros professôres e professoras presentes participado dos debates. As sessões foram presididas pelo professor Carlos Maciel, pelo técnico de Educação Moreira de Sousa e as duas últimas pelo orientador do Centro, o antropólogo e sociólogo Gilberto Freyre. (Boletim Mensal do CBPE, n. 17, dezembro, 1958, p. 11)

A leitura do trecho revela que Freire recebeu um convite oficial para o papel de comentarista do curso. Deste modo, foram estabelecidos os primeiros passos de sua trajetória intelectual no Centro de Recife. Entretanto, é interessante analisar o relato sobre o Encontro Nacional de Educadores para o Desenvolvimento que teve a sua realização em dezembro de 1960.

De 14 a 15 de dezembro pp., realizou-se, no Recife, o Encontro Nacional de Educadores para o Desenvolvimento, promovido pela CNI, Sesi e Senai. Do encontro participaram: Dr. Carlos Frederico Maciel, diretor da DEPE, na qualidade de coordenador do grupo de estudo sôbre Faculdades de Filosofia - Formação do Magistério; Dr. Levy Cruz, diretor da DEPS, que apresentou um correlatório sôbre "O ensino das Ciências Sociais no Brasil; a prof a Graziela

${ }^{21}$ Sobre a identificação do projeto, CRR equivale a Centro Regional de Recife; o número 6 se refere à ordem de entrada geral, e o número 4 está relacionado ao ingresso do projeto na Divisão de Pesquisas Educacionais (DPE). 


\section{pro.posıções}

$e$-ISSN 1980-6248

http://dx.doi.org/10.1590/1980-6248-2015-0098

Peregrino, diretora da DAM, que apresentou um correlatório sôbre "O ensino comercial para o desenvolvimento" e a prof $f^{a}$ Maria de Jesus Albuquerque, assistente da DAM, como membro colaborador do grupo de estudos de "Ensino Normal". (Boletim Mensal do CBPE, 1961, n. 43, janeiro, p. 13)

Torna-se perceptível que a presença de Paulo Freire no CRPE-Recife foi marcada por interdições, haja vista que o exame dos promotores do evento relatado, muito especificamente o Sesi, onde Freire trabalhou até 1957, e as preocupações com as faculdades de Filosofia, o intelectual exercia a cátedra de professor de História e Filosofia da Universidade de Filosofia, demonstram um descompasso entre as tentativas de participação e os convites. Paulo Freire poderia dar uma contribuição inestimável ao evento.

Passados quase dois anos, o nome de Freire reapareceu no relatório do Diretor da Divisão de Estudos e Pesquisas Sociais, prof. Levy Cruz, elaborado no final do ano de 1960. O relatório trouxe um balanço dos estudos e das pesquisas planejados pelo Centro Regional.

O problema principal para a realização de todas estas pesquisas, será, mais uma vez, a disponibilidade de pessoal habilitado. Foi sobretudo esse problema que entravou a realização de algumas pesquisas planejadas para 1960, a saber "Caracterização sócio-cultural de uma comunidade da Paraíba - (Picuî)", que deveria ter sido feita em colaboração com a Campanha Nacional de Erradicação do Analfabetismo e "Relações entre escola e comunidade", cujas Coordenações seriam confiadas ao professor Paulo Freire, que por diversos motivos, não pode siquer (sic) concluir o planejamento detalhado. (Boletim Mensal do CBPE, 1961, n. 45, abril, p. 13)

Portanto, a notícia indica que Freire seria o coordenador de dois projetos de pesquisa que estavam sob a responsabilidade da Campanha Nacional de Erradicação do Analfabetismo (CNEA). A alegação de falta de tempo, uma possível negação tácita, pode ter representado um peso danoso em relação a convites futuros para outras pesquisas do Centro, haja vista que a CNEA era uma importante ação de parceria entre o governo federal e o CBPE. Mais ainda, uma temática cara ao intelectual e uma participação em pesquisa esperada por três anos. Na parte final deste texto, essa recusa será retomada e aprofundada.

Em 1963, Paulo Freire fez parte da equipe de professores do curso de Programação Educacional, responsável pela disciplina "Realidade Brasileira" em seis aulas. O curso se estendeu pelo período de 08 de janeiro a 23 de março.

Em colaboração com o D.A.F.T., da SUDENE, que financiará o curso e as bolsas de 45 alunos, de todos os estados do nordeste, com a finalidade de preparar pessoal para as atividades de 


\section{pro.posıções \\ $e$-ISSN 1980-6248}

http://dx.doi.org/10.1590/1980-6248-2015-0098

planejamento educacional em função dos recursos do Plano Nacional de Educação, da Aliança para o Progresso e da própria SUDENE. (Boletim Mensal do CBPE, n. 67, fevereiro, p. 17)

Esses são os registros escritos da presença do intelectual que ajudam a mensurar o que, antes deste texto, sequer estava mapeado. De certo, Paulo Freire ministrou palestras, teve outros projetos, e atividades no âmbito do Centro Regional de Pesquisas Educacionais do Recife. Inclusive, o acervo do Centro Regional, a biblioteca da Fundação Gilberto Freyre e, mais importante ainda, os Cadernos Educação e Região (o boletim interno do CRPE-Recife) podem ser fontes preciosas para o preenchimento das lacunas deste mapeamento. Materiais instigantes para novas pesquisas que fogem ao espaço dedicado a este artigo.

\section{Considerações finais}

As relações entre memória e esquecimento pautam estas considerações. São apenas tentativas de buscas que poderiam contribuir para as elucidações em relação ao apagamento ou autoapagamento da trajetória de Paulo Freire no Centro Regional de Pesquisas Educacionais do Recife.

A primeira aproximação está relacionada à inconstância desta participação, conforme as fontes estudadas. Tal situação pode ter ocasionado a desvalorização da presença de Freire nas atividades do Centro tanto por parte do educador quanto dos estudiosos da sua obra.

Uma segunda trilha de análise tem relação com o provável estabelecimento de um marco, de uma espécie de ponto zero na trajetória do intelectual: a experiência de alfabetização em Angicos no ano de 1963. Uma marca que ofuscou - até certo momento da trajetória de Freire - as experiências no SESI e na Universidade de Pernambuco. Se confirmada a correção desta trilha, torna-se possível explicar o esquecimento da experiência no Centro Regional de Pesquisas Educacionais do Recife pois, a partir de 1980, houve um intenso processo de apagamento da história das instituições que, segundo alguns autores de visão ortodoxa, foram dirigidas ou criadas por intelectuais classificados como liberais e propensos a acordos e convênios com as nações tidas como imperialistas.

Uma situação vivenciada pelo próprio CBPE que foi criado e dirigido por Anísio Teixeira e seus colaboradores, dentre os quais destaco: Péricles Madureira de Pinho, Jayme 


\section{pro.posıções}

$e$-ISSN 1980-6248

http://dx.doi.org/10.1590/1980-6248-2015-0098

Abreu e Darcy Ribeiro. Dessa maneira, o apagamento da história do CBPE pode ter - num efeito cascata - ocasionado o mesmo processo em relação aos seus centros regionais de pesquisa $^{22}$.

É necessário aduzir aos pressupostos já levantados a ausência desta experiência de pesquisas e estudos regionais na própria obra de Paulo Freire, seja na sua produção teórica individual, seja na sua produção compartilhada. Neste aspecto, é revelador que, no livro Aprendendo com a própria história, em parceria com Sérgio Guimarães, exista um capítulo intitulado "Pré-64" e que nele não se encontre referência ao Centro Regional de Pesquisas Educacionais do Recife. É provável que os acordos e os convênios firmados pelo CBPE com o Programa de Assistência Brasileiro-Americana ao Ensino Elementar (PABAEE), a UNESCO, a Organização dos Estados Americanos (OEA) e com a Aliança para o Progresso (especialmente, quanto à última pelo seu caráter intervencionista por parte do governo norte-americano no contexto da Guerra Fria) tenham levado Freire ao afastamento das ações conjuntas e dos trabalhos coletivos no CRPE-Recife. Não se trata de uma especulação gratuita. Em depoimento em 1987 sobre o papel da Aliança para o Progresso no contexto dos anos 1960, Freire afirma

a Aliança para o Progresso, ferindo determinados dispositivos constitucionais brasileiros, fazia convênios diretamente com os governos de Estado, em vez de fazê-los com o governo federal. Desse modo ela atendia, no Nordeste, aos governos que tendiam a opor-se ou se opunham abertamente à orientação federal, numa demonstração, portanto, de que a Aliança para o Progresso tinha uma estratégia de enfraquecimento da força do governo federal. (Freire \& Guimarães, 1987, p.6)

Não está em julgamento o esquecimento operado por diferentes intelectuais e nem por Paulo Freire. O esquecimento é parte da memória. Está em jogo a compreensão das possíveis causas deste ato: por quê? Um complexa indagação. Difícil tentativa de resposta, haja vista que as fontes indicam não só a presença de Paulo Freire no CRPE-Recife como também de forma concomitante a sua participação na Universidade de Pernambuco, na SUDENE e no Movimento de Cultura Popular, ou seja, instituições em diálogo e com afinidades temáticas.

Independentemente da correção ou não das trilhas estabelecidas, as portas e as janelas estão abertas para aqueles que desejarem investigar a atuação de Paulo Freire em outras

\footnotetext{
22 Sobre a tentativa de apagamento da experiência do CBPE, consultar: Mendonça, A. W. P. C. (1997). O CBPE: um projeto de Anísio Teixeira. In A. W. P. C. Mendonça, \& Z. Brandão, Z. (Orgs.), Por que não lemos Anísio Teixeira? Rio de Janeiro: Ravil.
} 


\section{pro.posıções \\ $e$-ISSN 1980-6248}

http://dx.doi.org/10.1590/1980-6248-2015-0098

instituições, antes do golpe civil-militar de 1964. Investigações que, por certo, contribuirão para a historiografia da educação brasileira. Educação brasileira que tem em Paulo Freire um dos expoentes não só pelas teorias e práticas pedagógicas, mas também pela capacidade de persistir, ouvir e fazer do diálogo um ato amoroso.

Mais do que isto, vale ler e reler a obra daquele que é considerado por Lei (Lei 12.612, de 13 de abril de 2012.) no campo dos valores proclamados e por diversos professores no campo dos valores reais o Patrono da Educação Brasileira.

\section{Referências}

Becker, J. (2002). O handicap do a posteriori. In M. de M. Ferreira, \& J. Amado (Orgs.), Usos e abusos da história oral. Rio de Janeiro: Editora FGV.

Botelho, A., Bastos, E. R., \& Bôas, G. V. (Orgs.). (2008). O moderno em questão: a década de 1950 no Brasil. Rio de Janeiro: Topbooks.

Brasil. Ministério da Educação e Cultura. Instituto Nacional de Estudos Pedagógicos. Boletim Mensal do Centro Brasileiro de Pesquisas Educacionais (1957-1963) (n. 1 ao 77). Rio de Janeiro: CBPE/INEP/MEC.

Certeau, M. de. (2004). A invenção do cotidiano: 1. artes de fazer. Petrópolis: Vozes.

Elias, N. (1994). A sociedade dos indivíduos. Rio de Janeiro: Jorge Zahar.

Ferreira, M. S. (2008, maio/agosto). Os Centros de Pesquisas Educacionais do INEP e os estudos em Ciências Sociais sobre a educação no Brasil. Revista Brasileira de Educação, 13(38),279-411.

Ferreira, J., \& Delgado, L. de A (Orgs). (2003). O Brasil republicano - v. 3. O tempo da experiência democrática: da democratização de 1945 ao golpe civil-militar de 1964. Rio de Janeiro: Civilização Brasileira.

Freire, P., \& Guimarães, S. (1987) Aprendendo com a própria história. Rio de Janeiro: Paz e Terra. 


\section{pro.posıções \\ $e$-ISSN 1980-6248}

http://dx.doi.org/10.1590/1980-6248-2015-0098

Freitas, M. C. de. (1999). A pesquisa educacional como questão intelectual na história da educação brasileira. In M. C. Freitas (Org.), Memória intelectual da educação brasileira. Bragança Paulista: EDUSF.

Gouvêa, F. (2001). Um percurso com os boletins da CAPES: a contribuição de Anísio Teixeira para a institucionalização da pós-graduação no Brasil. Dissertação de Mestrado, Pontifícia Universidade Católica do Rio de Janeiro, Rio de Janeiro.

Gouvêa, F. (2008). Tudo de novo no front: o impresso como estratégia de legitimação do Centro Brasileiro de Pesquisas Educacionais. Tese de Doutorado, Pontifícia Universidade Católica do Rio de Janeiro, Rio de Janeiro.

Halbwachs, M. (2006). A memória coletiva. São Paulo: Centauro.

Instituto Paulo Freire. Recuperado em 11 de maio de 2015, de http://www.paulofreire.org/

Meucci, S. (2015, abril). Gilberto Freyre no comando do Centro Regional de Pesquisas Educacionais do Recife: educação em debate (1957-1964). Sociologia \& Antropologia, 05(1),129-155.

Sanchez, L., \& Gouvêa, F. (2011). Duas instituições, duas histórias, uma intenção: a utilização das "novas" tecnologias no cotidiano da formação de professores In L. M. T. Oliveira, \& A. Berenblum (Orgs.), Educação: diálogos do cotidiano (1a ed., pp. 97-122). Rio de Janeiro: Outras Letras.

Sirinelli, J. (2003). Os intelectuais. In R. Rémond (Org.), Por uma história política (2a ed., p. 231-270). Rio de Janeiro: Editora FGV.

\section{Legislação}

Decreto n.38.460, de 28 de dezembro de 1955. (1955). Institui o Centro Brasileiro de Pesquisas Educacionais e Centros Regionais no âmbito do Instituto Nacional de Estudos e Pesquisas Educacionais, do Ministério da Educação e Cultura. Recuperado em 15 de junho de 2015, de http://www2.camara.leg.br/legin/fed/decret/1950-1959/decreto38460-28-dezembro-1955-334313-republicacao-49484-pe.html. 


\section{pro.posıções \\ $e$-ISSN 1980-6248}

http://dx.doi.org/10.1590/1980-6248-2015-0098

Lei n. 12.612, de 13 de abril de 2012. (2012). Declara o educador Paulo Freire Patrono da Educação Brasileira. Recuperado em 10 de junho de 2015, de http://www.planalto.gov.br/ccivil_03/_Ato2011-2014/2012/Lei/L12612.htm.

Submetido à avaliação em 13 de agosto de 2015; revisado em 16 de dežembro de 2015; aceito para publicação em 19 de maio de 2017. 